\title{
PENGEMBANGAN METODE CONTEXT CLUES UNTUK MENINGKATKAN KETERAMPILAN MEMBACA MAHASISWA SEMESTER II
}

\author{
Desi Sri Astuti', Finny Anita², Maliqul Hafis ${ }^{3}$ \\ ${ }^{1}$ IKIP PGRI Pontianak \\ ${ }^{2}$ IKIP PGRI Pontianak \\ ${ }^{3}$ IKIP PGRI Pontianak \\ desisa28@gmail.com
}

\begin{abstract}
Abstrak
Mengembangkan bahan ajar menggunakan metode Context Clues dalam peningkatan kemampuan keterampilan membaca pada mata kuliah Academic Reading mahasiswa prodi Pendidikan Bahasa IKIP PGRI Pontianak. Metodologi penelitian ini adalah disain pengembangan dengan melalui tahapan yang terdiri dari Penelitian dan pengumpulan data yang meliputi pengukuran kebutuhan, studi literatur, penelitian dalam skala kecil, dan pertimbangan-pertimbangan dari segi nilai, perencanaan (planning), pengembangan draf produk, pengembangan bahan pembelajaran, proses pembelajaran, dan instrumen evaluasi, uji coba lapangan awal, merevisi hasil uji coba, uji coba lapangan utama, penyempurnaan produk hasil uji lapangan, uji pelaksanaan lapangan, penyempurnaan produk akhir, diseminasi dan implementasi. . Implikasi penerapan metode Context Clues dalam pembelajaran Academic Reading dapat meningkatkan daya berfikir kritis, analitis serta kemampuan membaca mahasiswa.
\end{abstract}

Kata kunci : context clues, academic reading, pengembangan

\begin{abstract}
Developing teaching materials using the Context Clues method in improving the ability of reading skills in the Academic Reading course of Language Education students at IKIP PGRI Pontianak in the academic year 2017/2018. The methodology of this research is development design through stages consisting of research and data collecting which includes measurement of needs, study of literature, research on a small scale, and considerations in terms of value, planning, development of draft products, development of learning materials, learning processes, and evaluation instruments, preliminary field trials, revising the results of trials, main field trials, improving product results from field tests, field implementation tests, final product improvements, dissemination and implementation. . The implications of applying the Context Clues method in learning Academic Reading can improve the power of critical thinking, analytics and student reading skills.
\end{abstract}

Key word : perception, the role Lecturer Academic

\section{PENDAHULUAN}

Membaca memungkinkan orang untuk mengetahui informasi dari berbagai teks, ditulis atau dicetak, informasi dari surat kabar, majalah, iklan, brosur, dan sebagainya. Membaca adalah kegiatan yang penting dan menjadi lebih penting di 
dunia modern ini, di mana perkembangan dalam setiap aspek kehidupan terjadi sangat cepat. Sebagai bagian dari kemampuan bahasa, membaca memainkan peran penting bagi keberhasilan pembelajaran bahasa.

Menurut Aebersold dan Field (1997: 15), membaca adalah apa yang terjadi ketika orang melihat teks dan menetapkan makna simbol-simbol yang ditulis dalam teks itu. Selain itu, William (1984: 12) mendefinisikan membaca sebagai proses dimana seseorang melihat dan memahami apa yang telah ditulis. Dari kedua definisi, dapat disimpulkan bahwa membaca adalah proses menempatkan makna untuk mendapatkan informasi dengan memahami teks tertulis. Para pembaca juga memiliki pendapat yang berbeda dan unik tentang teks

Mata kuliah Membaca (Reading) yang ada pada Program Studi Pendidikan Bahasa Inggris Universitas IKIP PGRI Pontianak Kurikulum 2015 dengan tingkatannya masing-masing pada setiap semester adalah Basic Reading, Academic Reading, dan Advanced Reading. Materi ajar/ Bahan ajar untuk MK reading ditentukan oleh dosen pengampu mata kuliah. Perkembangan mutu pengajaran dan kualitas pengajar yang diterapkan dosen/pengajar di prodi pendidikan Bahasa Inggris IKIP PGRI Pontianak sangat berpengaruh dalam pencapian hasil belajar mahasiswa di kelas. Ada beragam cara perbaikan mutu dan kualitas pengajaran, dari metode hingga bahan ajar. Perbaikan ini perlu dilakukan agar kualitas calon guru yang dihasilkan diharapkan dapat memuaskan stakeholders dan meningkatkan demands alumni prodi pendidikan Bahasa Inggris IKIP PGRI Pontianak dalam persaingan global ketika mereka terjun ke masyarkat. Terkadang, ada beberapa kendala yang ditemui ketika mahasiswa mengikuti mata kuliah Reading diantaranya adalah bahan ajar yang monoton serta tidak dipersiapkannya metode yang tepat dan cepat agar penguasaan Reading dapat dicapai dengan mudah. Bagi banyak orang membaca adalah suatu tugas yang berat. Menebak kata yang tersirat dari sebuah teks merupakan hal yg sulit, sehingga mahasiswa terus membuka kamus untuk mendapatkan makna yang dimaksud. Berbeda dengan metode Context Clues, mahasiswa bisa langsung menebak makna kata dengan mengacu pada petunjuk yang ada di dalam kalimat. Context Clues merupakan satu metode pembelajaran yang mudah dan 
menyenangkan yang bisa merangsang mahasiswa untuk menebak arti kata dengan petunjuk yang ada dalam teks. A context clue is a source of information about a word that helps readers understand the word. This word or phrase offers insight, either directly or indirectly, into the word's meaning.

Melalui metode ini, peneliti berharap akan menemukan satu metode pengajaran Reading khususnya pada mata kuliah Academic Reading baru yang lebih mudah dan menyenangkan dengan memberikan petunjuk-petunjuk kata yang semakna dengan kata yang ditebak sehingga akan memperkaya kosa kata mahasiswa dalam mengembangkan kalimat dengan tujuan peningkatan kemampuan mahasiswa pada mata kuliah Academic Reading di semester II Prodi Pendidikan Bahasa IKIP PGRI Pontianak.

\section{METODE}

\section{Desain Penelitian}

Penelitian ini menggunakan metode penelitian pengembangan (Research and Development). Menurut Sugiyono (2007 : 297) metode penelitian dan pengembangan (Research and Development) adalah “....metode penelitian yang digunakan untuk menghasilkan produk tertentu dan menguji keefektifitasan produk tersebut".

\section{A. Prosedur Pengembangan}

Borg dan Gall (1983: 775) mengajukan serangkaian tahap yang harus ditempuh dalam pendekatan ini, yaitu "research and information collecting, planning, develop preliminary form of product, preliminary field testing, main product revision, main field testing, operational product revision, operational field testing, final product revision, and dissemination and implementation". Secara konseptual, pendekatan penelitian dan pengembangan mencakup 10 langkah umum.

1. Penelitian dan pengumpulan data (research and information collecting) yang meliputi pengukuran kebutuhan, studi literatur, penelitian dalam skala kecil, dan pertimbangan-pertimbangan dari segi nilai.

2. Perencanaan (planning) yaitu menyusun rencana penelitian, meliputi kemampuan-kemampuan yang diperlukan dalam pelaksanaan penelitian, 
rumusan tujuan yang hendak dicapai dengan penelitian tersebut, desain atau langkah-langkah penelitian, dan kemungkinan dalam lingkup terbatas.

3. Pengembangan draf produk (develop preliminary form of product). Pengembangan bahan pembelajaran, proses pembelajaran, dan instrumen evaluasi.

4. Uji coba lapangan awal (preliminary field testing). Selama uji coba dilakukan pengamatan, wawancara dan pengedaran angket.

5. Merevisi hasil uji coba (main product revision).

6. Uji coba lapangan (main field testing).

7. Penyempurnaan produk hasil uji lapangan (operasional product revision).

8. Uji pelaksanaan lapangan (operasional field testing).

9. Penyempurnaan produk akhir (final product revision).

10. Diseminasi dan implementasi (dissemination and implementation).

\section{Obyek dan Subyek Penelitian}

Obyek penelitian ini adalah metode Context Clues. Subyek penelitian ini adalah mahasiswa semester 2 kelas B Sore yang berjumlah 30 orang.

\section{HASIL DAN PEMBAHASAN}

Metode pembelajaran yang dikembangkan dalam mata kuliah ini adalah metode pembelajaran Context Clues mengadopsi model pengembangan Borg \& Gall (1983:775) yang terdiri dari Penelitian dan pengumpulan data (research and information collecting) yang meliputi pengukuran kebutuhan, studi literatur, penelitian dalam skala kecil, dan pertimbangan-pertimbangan dari segi nilai, perencanaan (planning), pengembangan draf produk, pengembangan bahan pembelajaran, proses pembelajaran, dan instrumen evaluasi, uji coba lapangan awal, merevisi hasil uji coba, uji coba lapangan utama, penyempurnaan produk hasil uji lapangan, uji pelaksanaan lapangan, penyempurnaan produk akhir, diseminasi dan implementasi.

Rincian waktu dan kegiatan yang dilakukan dalam mengembangkan metode pembelajaran ini dapat dilihat pada tabel 4.1 berikut : 
Table 1

Rincian Waktu dan Kegiatan Pengembangan Metode Context Clues

\begin{tabular}{|c|c|c|c|}
\hline No & Tanggal & Nama kegiatan & Hasil yang Diperoleh \\
\hline 1 & 29 Maret 2018 & Studi Literatur & $\begin{array}{l}\text { Mengkaji secara teoritik } \\
\text { pengembangan metode } \text { Context } \\
\text { Clues dan mengetehui masalah } \\
\text { yang di hadapi mahasiswa pada } \\
\text { mata kuliah Academic } \\
\text { meading } \\
\text { mahasiswa }\end{array}$ \\
\hline 2 & $\begin{array}{l}2-9 \\
2018\end{array}$ & $\begin{array}{l}\text { Pengumpulan } \\
\text { data }\end{array}$ & $\begin{array}{l}\text { Data-data materi ajar Academic } \\
\text { Reading yang kemudian } \\
\text { pembahasan menggunakan } \\
\text { metode Context Clues }\end{array}$ \\
\hline 3 & $\begin{array}{l}10-28 \text { Mei } \\
2018\end{array}$ & $\begin{array}{l}\text { Penyusunan } \\
\text { rencana dan } \\
\text { pengembangan } \\
\text { desain metode } \\
\text { Context Clues }\end{array}$ & $\begin{array}{l}\text { Menghasilkan perangkat } \\
\text { pembelajaran, materi ajar berupa } \\
\text { menggunakan metode Context } \\
\text { Clues }\end{array}$ \\
\hline 4 & 3 Mei 2018 & $\begin{array}{l}\text { Uji } \\
\text { lapangan tahap } 1 \\
\text { test awal }\end{array}$ & $\begin{array}{l}\text { Menemukan gambaran umum } \\
\text { dari metode Context Clues }\end{array}$ \\
\hline 5 & $\begin{array}{l}7-28 \text { Mei } \\
2018\end{array}$ & $\begin{array}{l}\text { Perbaikan produk } \\
\text { awal }\end{array}$ & $\begin{array}{l}\text { Membuat draft metode Context } \\
\text { Clues }\end{array}$ \\
\hline 6 & 4 Juni 2018 & $\begin{array}{l}\text { Uji coba utama } \\
\text { serta pengisian } \\
\text { angket }\end{array}$ & $\begin{array}{l}\text { Menemukan kekurangan dan } \\
\text { kelebihan dari metode Context } \\
\text { Clues }\end{array}$ \\
\hline 7 & $\begin{array}{l}11-25 \text { Juni } \\
2018\end{array}$ & $\begin{array}{l}\text { Perbaikan hasil } \\
\text { ujicoba lebih luas }\end{array}$ & $\begin{array}{l}\text { Penyempurnaan metode Context } \\
\text { Clues }\end{array}$ \\
\hline 8 & $\begin{array}{lll}2- & 16 & \text { Juni } \\
2018 & & \\
\end{array}$ & Validasi Produk & $\begin{array}{l}\text { Metode Context Clues yang siap } \\
\text { pakai }\end{array}$ \\
\hline 9 & $\begin{array}{l}30 \text { Juli }-18 \\
\text { Agustus } 2018\end{array}$ & $\begin{array}{l}\text { Penulisan } \\
\text { laporan }\end{array}$ & Laporan Hasil Penelitian \\
\hline
\end{tabular}

1. Tahap Studi Literatur

Berdasarkan observasi langsung dan hasil diskusi dengan dosen pengampu mata kuliah, peneliti memperoleh beberapa informasi, yaitu:

a. Minimnya pemanfaatan metode-metode yang ada

b. Selama proses belajar mengajar dosen lebih cenderung lebih aktif dibandingkan dengan mahasiswa yang lebih banyak mendengarkan penjelasan dosen 
Oleh karena itu, menurut peneliti perlu dikembangkan metode pembelajaran agar mahasiswa lebih aktif serta memberikan keterampilan yang belum didapatkan mahasiswa sebelumnya.

2. Tahap Pengumpulan Data

Pada tahap ini kegiatan yang dilakukan adalah mengumpulkan datadata yang dapat dijadikan sumber pembuatan materi ajar yang menggunakan metode Context Cluesse

3. Tahap Penyusunan dan Pengembangan

Pada tahap ini kegiatan yang dilakukan yaitu membuat perangkat pembelajaran yang menggunakan metode Context Clues

4. Tahap Uji Coba lapangan Tahap 1

Uji coba lapangan tahap 1 dilakukan dengan memberikan tes awal untuk mengetahui gambaran umum mengenai metode Context Clues.

5. Tahap Perbaikan Produk Awal

Gambaran umum yang didapat melalui pengisian angket menjadi dasar tentang pembuatan draft metode Context Clues

6. Tahap Uji coba Utama

Setelah adanya draft metode Context Clues, dilakukan uji coba kembali untuk mengetahui kekurangan dan kelebihan dari metode Context Clues, serta menyebarkan angket tentang penerapan metode Context Clues.

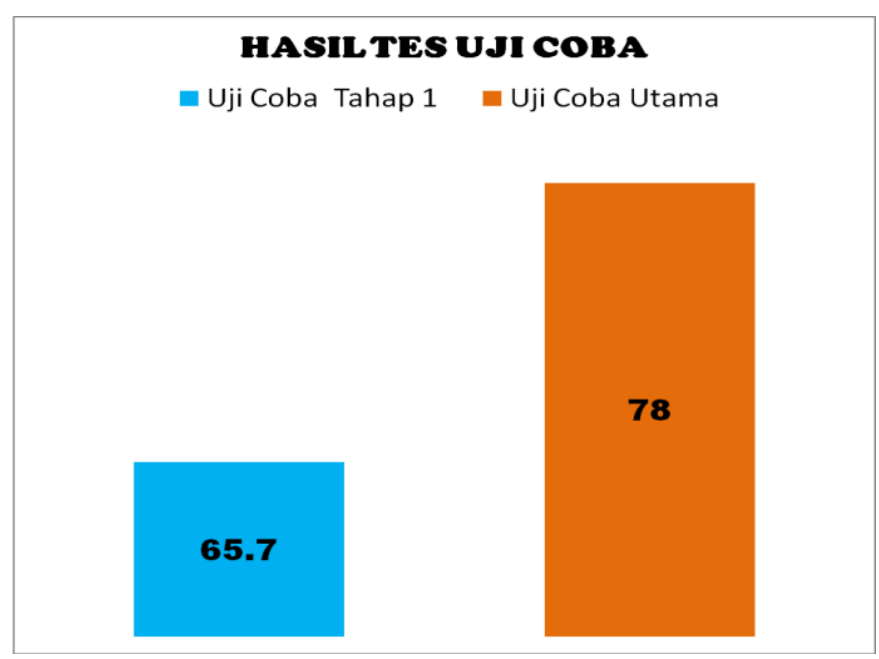




\section{Gambar 1. Hasil Tes Uji Coba}

7. Tahap Perbaikan Hasil Ujicoba Lebih Luas

Setelah melakukan ujicoba draft metode Context Clues dan mengetahui kekurang dan kelebihan dari metode Context Clues maka dilakukan penyempurnaan metode Context Clues

8. Tahap Validasi Produk

Pada tahap validasi produk, dilakukan oleh dosen yang menguasi tentang metode Context Clues

9. Tahap Penulisan Laporan

Setalah semua tahapan sudah dilaksakan maka tahapan selanjutnya adalah memberikan hasil laporan yang kemudian akan dipublikasikan ke Jurnal.

\section{PEMBAHASAN}

Pada hasil penelitian mengenai Pengembangan Metode Context Clues untuk Meningkatkan Keterampilan Membaca Mahasiswa Jurusan Pendidikan Bahasa Inggris Universitas IKIP PGRI Pontianak sangat terlihat dalam mata kuliah Academic Reading . sebelum dikenalkannya metode Context Clues kepada mahasiswa, mahasiswa diberikan beberapa pertanyaan mengenai apakah mereka familier atau tidak mengenai metode tersebut. Dapat dilihat dari beberapa jawaban mahasiswa bahwa mereka belum mengenal mengenai metode Context Clues, mengapa metode itu penting digunakan dalam membaca, dan mengapa mata kuliah Reading ataupun membaca merupakan salah satu mata kuliah yang membosankan bagi mereka.

Dapat di lihat dalam uji coba tahap I dimana hasil nilai rata-rata yang diperoleh 65.7 dengan kategori cukup, nilai tersebut menandakan bahwa mahasiswa pada dasarnnya masih mengharapkan metode yang digunakan dalam membaca lebih menarik dan tidak membosankan sehingga mereka mampu membaca suatu teks ataupun jurnal tanpa harus jenuh dan merasa bosan. Sering kali memang kita temukan, dikarenakan suatu teks ataupun jurnal tersebut memiliki banyak kata- kata yang sulit, mahasiswa menjadi jenuh dan hanya 
sekedar mencoba mencari kata- kata yang sulit di dalam kamus sehingga lupa untuk memahami isi ataupun makna dalam suatu teks ataupun jurnal.

Disini peran peneliti dan dosen- dosen tim Academic Reading adalah untuk mengenalkan metode Context Clues dan mengajarkan kepada mahasiswa bahwa jika mereka menemukan hambatan mengenai kata- kata sulit mereka tidak harus langsung membuka kamus, tetapi mereka dapat menemukan arti dari kata sulit tersebut di kalimat selanjutnya dengan cara memahami dan mengerti mengenai metode Context Clues. Adapun Group Discussion ini dilakukan bukan hanya hanya agar mahasiswa mengerti dan memahami tetapi juga agar metode ini lebih sering dipergunakan dalam membaca teks ataupun jurnal agar dapat menghemat waktu tanpa harus membuka kamus berulang- ulang. Ketika metode ini diterapkan untuk lebih dalam lagi setelah dengan adanya perbaikan produk awal, melalui tes uji coba utama ternyata hasil nilai rata-rata mahasiswa meningkat dengan nilai 78 kategori baik yang dimana pada uji tes tahap 1 perolehan nilai rata-rata 65.7 dengan kategori cukup.

Metode Context Clues ini sangat bermanfaat bagi mahasiswa, terutama dalam membaca ataupun dipergunakan dalam skills lainnya, misalkan dalam menulis ataupun mendengarkan. Jadi, dapat kita simpulkan bahwasanya sebelum menggunakan metode Context Clues mahasiswa sangat sulit untuk memahami suatu teks ataupun jurnal dan selalu membuka kamus secara berulang- ulang, sedangkan setelah mendapatkan arahan mengenai penjelasan apa itu metode Context Clues dengan menjelaskan dan mengadakan Group Discussion mahasiswa lebih mudah dalam memahami inti ataupun makna dalam suatu teks ataupun jurnal tanpa harus terlalu sering membuka kamus sehingga lebih efisien ataupun hemat dalam penggunan waktu dalam pengerjaan latihan- latihan.

Hasil dari pengisian angket yang disebarkan, dapat ditarik kesimpulan bahwasannya mahasiswa menikmati serta merasakan manfaat langsung dalam pembelajaran mata kuliah Academic Reading melalui metode Context Clues, mahasiswa dapat mengerti isi dari bacaan dengan cepat serta dapat mengingat kosakata dengan mudah. 


\section{SIMPULAN}

Berdasarkan dari hasil pembelajaran mengenai Pengembangan Metode Context Clues untuk Meningkatkan Keterampilan Membaca Mahasiswa Jurusan Pendidikan Bahasa Inggris Universitas IKIP PGRI Pontianak dapat disimpulkan bahwa: (1) Pembelajaran dengan menggunakan metode Context Clues dapat meningkatkan kemampuan membaca mahasiswa dan pemahaman mengenai isi serta kata- kata sulit. Mahasiswa mengerti dan memahami mengenai metode Context Clues dan cara penerapannya dalam membaca teks ataupun jurnal yang tersedia; (2) Adapun penerapan metode Context Clues ini dilakukan pada mata kuliah Academic Reading mahasiswa semester 2 kelas B sore yang berjumlah 30 mahasiswa. Adapun yang dilakukan bukan hanya menerangkan apa itu metode Context Clues oleh dosen pengampu tetapi juga mengadakan Group Discussion agar mahasiswa lebih mengerti dan memahami mengenai metode tersebut; (3) Implikasi penerapan metode Context Clues dalam pembelajaran Academic Reading dapat meningkatkan daya berfikir kritis, analitis serta kemampuan membaca mahasiswa. Adapun mengenai metode Context Clues dapat dilihat di RPP dan Silabus mata kuliah Academic Reading, dimana dosen yang bersangkutan memaparkan apa itu metode Context Clues dan bagaimana penerapannya dalam membaca.

\section{DAFTAR PUSTAKA}

Aebersold, J. A., \& M. L. Field. (1997). From Reading to Reading Teacher: Issues and Strategies for Second. Language Classrooms. Cambridge: Cambridge

Borg, W. R., \& Gall, M. D (1983). Educational Research An Introduction. New York. Longman.

Sugiyono. (2007). Metode Penilaian Pendidikan (Pendekatan Kuantitatif, Kualitatif dan R/D). Bandung: Alfabeta.

William, E. (1984). Reading in the Language Classroom. London: Modern English Publication. 